\title{
Synthesis and characterization of innovative insulation materials
}

\author{
Aggeliki Skaropoulou, Afroditi Ntziouni, Dimitris Kioupis, Sotiris Tsivilis and Glikeria Kakali \\ National Technical University of Athens, School of Chemical Engineering, Athens, Greece
}

\begin{abstract}
Insulation elements are distinguished in inorganic fibrous and organic foamed materials. Foamed insulation materials are of great acceptance and use, but their major disadvantage is their flammability. In case of fire, they tend to transmit the flame producing toxic gases. In this paper, the synthesis and characterization of innovative inorganic insulation materials with properties competitive to commercial is presented. Their synthesis involves the mixing of inorganic raw material and water with reinforcing agent or/and foaming agent leading to the formation of a gel. Depending on raw materials nature, the insulation material is produced by freeze drying or ambient drying techniques of the gel. The raw material used are chemically benign and abundantly available materials, or industrial by-products and the final products are non-toxic and, in some cases, non-flammable. Their density and thermal conductivity was measured and found $0.02-0.06 \mathrm{~g} / \mathrm{cm}^{3}$ and 0.03-0.04 W/mK, respectively.
\end{abstract}

\section{Introduction}

In Greece, the first thermal regulation was established in 1979, which was replaced in 2010 by the energy efficiency building regulation. Furthermore, the energy consumption for heating and cooling needs in a building with and without insulation is 1:3. The lack of insulation, is both costly, because of increase in energy consumption, and environmental harmful, considering that, in Greece, $82 \%$ of buildings are built before 1980 and $45 \%$ of total energy consumption is due to the building sector with over than $65 \%$ consumed for cooling and heating.

As insulation materials are considered the ones that manage to trap air into their mass, providing energy independence in the spaces and thus ensuring a smooth season transition. They are characterized by the thermal conductivity coefficient. Insulation materials can be either inorganic fibrous elements (glass wool, rockwool, etc.), that are wide used in Europe (cover 60\% of European market), or organic foamed ones (expanded polystyrene - EPS, extruded polystyrene - XPS, polyurethane) that cover $80 \%$ of the domestic market.

Polystyrene-based insulation materials, are unique for external insulation, due to their low water absorption property. Their major disadvantages consist of the environmental impact and their flammability. During the production process of organic insulation materials, $\mathrm{CO}_{2}$ emissions are greater compared to the production of inorganic ones, while in case of fire they tend to transmit the flame, producing toxic gases which in most cases are responsible for the human losses [1].
Silica aerogels are a class of materials well known since 1930, with high specific surface area, high porosity, low density and low thermal resistance. Their synthesis involves the formation of a gel, and the removal of the liquid medium through supercritical drying [2, 3]. Over the past 20 years, the research community focuses on the use of various raw materials and the determination of the optimized synthesis conditions. Ambient drying of the formed gel instead of supercritical drying is gaining momentum as it is a safer and less costly procedure. Its synthesis constitutes the mixing of a silica source (TMOS, TEOS, PEDS) with ethanol or acetone in acid or base environment, the formation of gel, its polymerization and, finally, its drying [4-6]. While the received products exhibit excellent properties, the materials that are used as silica source are both expensive and hazardous. Recently, synthesis of insulation materials using as raw materials either clay (clay based aerogels) which are chemically benign and abundant available or industrial by-products (silica based aerogels) gain ground. Synthesis route comprises the mixing of inorganic raw materials with water, reinforcing agent or/and binding agent (polyvinyl alcohol, casein, cellulose fiber, gelatin), and /or foaming agent (sodium dodecyl sulfate) to form a gel. The water is removed either by freeze drying under high vacuum or by ambient drying techniques [7-14]. Depending on the needs and use, products with different properties and structure can occur.

The fabrication of eco-friendly insulation materials, safe to produce and install and with properties competitive to commercial, constitutes a challenge. In this paper, the synthesis and the characterization of innovative, inorganic insulation materials with properties 
competitive to commercial products is presented. Depending on the raw materials nature and the synthesis procedure, insulation materials with different properties and lamellar or foamed structure can be produced.

\section{Lamellar structure insulation materials}

From all clays, sodium montmorillonite (Na-MMT), is preferred because of its swelling property, high cation exchange capacity, high aspect ratio and large surface area, rendering it ideal for aerogel formation [14, 15]. This aerogel is synthesized during the freezing and freeze-drying of a gel, which is formed during the mixing of Na-MMT with water. Particularly, during the hydration of Na-MMT, water molecules penetrate between the clay layers, increasing the volume of the clay by up to two times. During freezing the growing ice fronts cause alignment/shearing of the Na-MMT particles along the ice crystal faces. After high vacuum sublimation, air is trapped in the place of ice crystals, forming a lightweight material with lamellar structure $[10,12,14,16]$. The formed clay aerogel is a material with low density, low thermal conductivity and low mechanical strength, which can be improved by the use of a reinforcement agent [17-21].

Different batches of MMT (Na-MMT, commercial product, Imerys) or organically modified MMT (nanoclay /sigma Aldrich, cloisite /BYK), along with various reinforcement agents, such as polyvinyl alcohol (PVA, 98-99\% hydrolyzed, Mw: 31,000-50,000, Acros Organics), casein (Sigma Aldrich) or cellulose fibers (Sigma Aldrich), were investigated. Different freezing temperatures $\left(-40^{\circ} \mathrm{C},-80^{\circ} \mathrm{C}\right.$, gradual freezing, Freezer model: Arctico) were also examined and the produced samples were placed in the freeze dryer of high vacuum (Scientz 50D, $\sim 1 \mathrm{~Pa}$ ). Na-MMT was mixed with deionized water in a slow shear rate mixer and the reinforcing agent was added in the clay suspension. In the case of PVA, a solution was prepared by dissolving PVA in water at $70-80^{\circ} \mathrm{C}$ until complete dissolution, while the rest reinforcing agents were used in powder form. The mixing of clay suspension with reinforcement agent lasted until fully homogenization of the mixture. The suspension was molded, placed in the freezer and then in the freeze dryer.

Raw materials and samples were characterized through X-Ray Diffraction (Advance B8 Brucker X-ray diffractometer, with $\mathrm{CuK} \alpha, \lambda=1,5405 \AA)$ and Fourier Transform IR spectrophotometer (Jasco 4200, 400-4000 $\mathrm{cm}^{-1}$ wavenumber, $\mathrm{KBr}$ technique, 1:200, $\left.8 \mathrm{t} / \mathrm{cm}^{2}\right)$. Density, thermal conductivity, water vapor absorption and fire resistance was calculated at the final products, while their structure was observed through scanning electron microscope (SEM, JEOL JSM-5600, equipped with OXFORD LINK ISIS 300 EDX) and stereoscope (Zeiss Stemi 2000C, connected with Axio Cam ErcS5). The density of the samples was calculated based on mass and volume measurements. The thermal conductivity was determined by means of the Heat Flow method, on a Netzsch HFM 436 lamda Heat Flow Meter, which meets the EN 12667 and ASTM C518 requirements (mean temperature: $10^{\circ} \mathrm{C}$, temperature difference: $10^{\circ} \mathrm{C}$ ). Water vapor sorption was determined according to ASTM C1104/ C1104M, a standard for unfaced insulation materials and fire resistance was ascertained according to DIN 4102, a test which measures the ignitability of building products subjected to direct impingement of flame.

\section{Foamed structure insulation materials}

Foamed insulation materials of inorganic nature can be produced by the combination of clay or industrial byproducts with a binding agent and a foaming agent. From all clays, sodium montmorillonite was preferred, as mentioned in previous section, while from industrial byproducts, silica fume, an amorphous, non-crystalline $\mathrm{SiO}_{2}$, an ultrafine by-product of the silicon and ferrosilicon alloy production was chosen. Raw materials are dispersed in insulation matrix. The matrix is consisted of a binding agent, which ascribes lattice stability, and a foaming agent, which contributes in porosity increase, leading to aerogels with lower density and thermal conductivity. Raw material is dispersed in the matrix, attributing volume stability and enhanced fire resistance due to its inorganic nature. Synthesis route comprises the dissolution of gelatin (binding agent) in water at $\sim 60^{\circ} \mathrm{C}$. Subsequently, gelatin solution is mixed with sodium dodecyl sulfate (SDS- foaming agent) until frothed into foam before adding the selected raw material. The foamed mixture is molded and either freezed and the ice is removed via sublimation, or dried at ambient conditions [22]. In every case, a lightweight material with foamed structure is obtained. Properties and characterization of raw materials and final products were defined according to methods mentioned above.

\section{Results and discussion}

Clay aerogels with Na-MMT and water alone, is very brittle, so PVA, casein or cellulose fibers (CF) were used as reinforcement agents. For the same content, only samples with PVA and casein were received as monoliths, as shown in Figure 1, with the ones with PVA to be more coherent. Cellulose fibers didn't seem to contribute in the specimen's rigidity. Freezing temperature was investigated and found that samples frozen at $-40^{\circ} \mathrm{C}$ showed lower values of density and thermal conductivity.

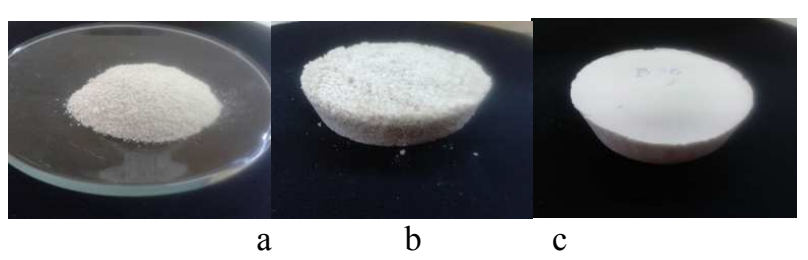

Fig. 1. Photos of the samples (a: CF/Na-MMT aerogels, b: Casein/Na-MMT aerogels, c: PVA/Na-MMT aerogels)

From all results, irrespective of synthesis procedure, it was concluded that increased content of raw materials leads to increased density, lower porosity and higher 
values of thermal conductivity. Indicatively, the results for the synthesis of lamellar structure insulation materials with PVA as reinforcement agent are presented in Figure 2 .

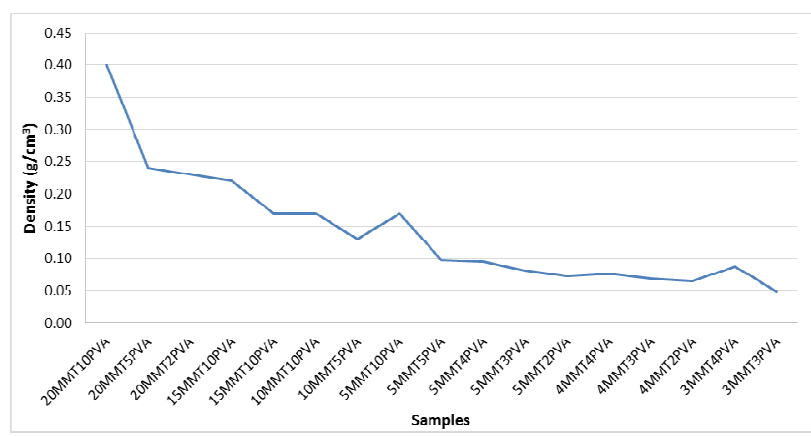

Fig. 2. Density of lamellar structure insulation materials (code name: xNa-MMTyPVA, where $\mathrm{x}, \mathrm{y}$ : Na-MMT, PVA content)

Synthesis of various samples of lamellar or foamed structure were carried out and the optimized conditions for low porosity and thermal conductivity compared to satisfying rigidity were found. Density and thermal conductivity values of these insulation materials are presented in Table 1, while their stereoscope images are presented in Figure 3.

Table 1. Density and thermal conductivity of synthesized insulation materials

\begin{tabular}{ccc}
\hline Materials characteristics & $\begin{array}{c}\text { Density } \\
\left(\mathrm{g} / \mathrm{cm}^{3}\right)\end{array}$ & $\begin{array}{c}\text { Thermal } \\
\text { conductivity } \\
(\mathrm{W} / \mathrm{mK})\end{array}$ \\
\hline $\begin{array}{c}\text { Na-MMT/Lamellar } \\
\text { structure/Freeze drying }\end{array}$ & 0.05 & 0.035 \\
$\quad$ Na-MMT/Foamed \\
structure/Freeze drying & 0.017 & 0.034 \\
$\begin{array}{c}\text { Silica fume/Foamed } \\
\text { structure/Freeze drying } \\
\text { Silica fume/Foamed } \\
\text { structure/ambient drying }\end{array}$ & 0.026 & 0.033 \\
\hline
\end{tabular}

In the case of freeze drying, foamed structure insulation materials shows an essential decrease in porosity compared to ambient drying, which does not imprint in thermal conductivity values. As it is observed from stereoscope images (Figure 3c, 3d), silica based insulation materials produced via ambient drying are more compact than the ones produced via freeze drying, which is in good accordance with the values of density and thermal conductivity.

Water moisture absorption and fire resistance were examined at materials of all synthesis procedure. Samples were exposed to $100 \%$ humidity and it was observed that the samples with lamellar structure had better behavior, as they manage to maintain their shape and their surface integrity. Foamed insulation materials probably because of their great open porosity might absorb greater amount of water vapor causing more intense deformation than the lamellar structure ones.

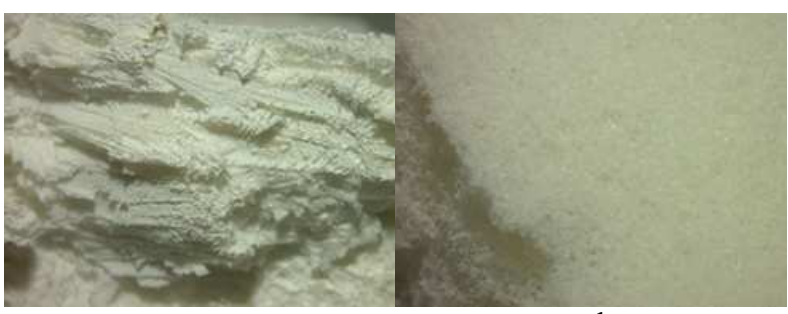

a b

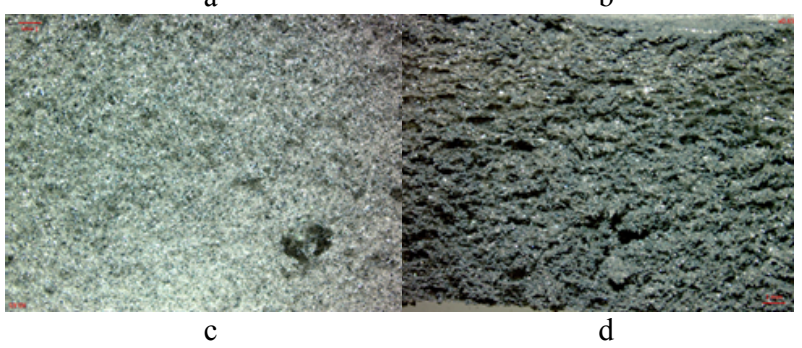

Fig. 3. Stereoscope images, a) Na-MMT/ Lamellar structure/ Freeze drying, b) Na-MMT/ Foamed structure/ Freeze drying, c) Silica fume/ Foamed structure/ Freeze drying, d) Silica fume/ Foamed structure/ Ambient drying

\section{Conclusions}

Two synthesis procedure of materials with high porosity and low thermal conductivity were investigated. The one involves the mixing of raw material with reinforcing agent, freezing and freeze drying of the suspension. The produced material has lamellar structure. The other procedure include the mixing of raw material with binding or foaming agent, followed either by freeze drying or by ambient drying. In this case, the produced material has a foamed structure, lower density than the lamellar structure products, but similar thermal conductivity values. Optimized synthesis were defined and, depending on procedure, density values were in the range $0.02-0.06 \mathrm{~g} / \mathrm{cm}^{3}$ and thermal conductivity values were in the range $0.03-0.04 \mathrm{~W} / \mathrm{mK}$. Clay based aerogels with lamellar structure are inflammable and less susceptible to water vapor sorption compared to foamed structure insulation materials either clay based or silica based.

\section{Acknowledgement}

This project was funding from $7^{\text {th }}$ Framework Programme (FP7-2013-NMP-ENV-EeB, "Multifunctional facades of reduced thickness for fast and cost-effective retrofitting, MF-Retrofit".

\section{References}

1. A.K. Karamanos, E. Giama, S. Chadiarakou, A.M. Papadapoulos., Heleco '05, 1-11 (2005)

2. J. Fricke, A. Emmerling, J. Am. Ceram. Soc. 75, 8, 2027-2035 (1992)

3. S.S. Kistler. J. Phys. Chem. 36, 1, 52-64 (1932)

4. A. Venkateswara Rao, E. Nilsen, M.A. Einarsrud. J. Non-Cryst. Solids, 296, 3, 165-171 (2001) 
5. S.D. Bhagat, , Y,-H Kim, Y.-S Ahn, J.-G. Yeo, App. Surf. Sci. 253, 6, 3231-3236 (2007)

6. F. Shi, L. Wang, J. Liu, Mater. Lett. 60, 29-30, 3718-3722 (2006)

7. Y. Wang, M.D. Gawryla, D.A. Schiraldi, J. APPL. POLYM. SCI. 129, 3, 1637-1641 (2013)

8. B. Lei, K. Shin, I. Jo, Y. Koh, H..Kim, Materials Chemistry and Physics, 145, 3, 397-402 (2014)

9. S.M. Alhassan, S. Qutubuddin, D.A. Schiraldi, Langmuir, 26, 14, 12198-12202 (2010)

10. T. Pojanavaraphan, D.A. Schiraldi, R. Magaraphan, Applied Clay Science, 50, 2, 271-279 (2010)

11. M. Sachithanadam, S.C. Joshi, Procedia Engineering, 75, 51-55 (2014)

12. H.V. Olphen, $15^{\text {th }}$ Conf on Clays and Clay Materials, 15, 423-435 (1967)

13. A.P. Perissinotto, C.M. Awano, F.S. de Vincente, D.A. Donatti, A. Mesquita, L.F. da Silva, D.R. Vollet, Microporous and Mesoporous Materials, 223, 196-202 (2016)

14. S.R. Hostler, A.R. Abramson, M.D. Gawryla, S.A. Bandi, D.A. Schiraldi, Int. J. .Heat .Mass Transfer, 52, 3-4, 665-669 (2009)

15. Y. Wang, S.M. Alhassan, V.H. Yang, D.A. Schiraldi, Composites Part B, 45, 1, 625-630 (2013)

16. S.A. Bandi, M. Bell, D.A. Schiraldi, Macromolecules, 38, 22, 9216-9220 (2005)

17. K. Finlay, M.D. Gawryla, D.A. Schiraldi, Ind. Eng. Chem. Res. 47, 3, 615-619 (2008)

18. T. Pojanavaraphan, R. Magaraphan, B. Chiou, D.A. Schiraldi, Biomacromolecules, 11, 10, 2640-2646 (2010)

19. L.S. Somlai, S.A. Bandi, D.A. Schiraldi, L.J. Mathias, AIChE J. 52, 3, 1162-1168 (2006)

20. A. Skaropoulou, D.Kioupis., S. Tsivilis, G. Kakali. Ashrae EinB2016, \#27, 1-7 (2016)

21. A. Skaropoulou, S.Tsivilis, G. Kakali. Ashrae EinB2014, \#110, 1-7 (2014).

22. M. Sachithanadam, S.C. Joshi, J. Mater. Sci., 49, 1, 163-179 (2014) 